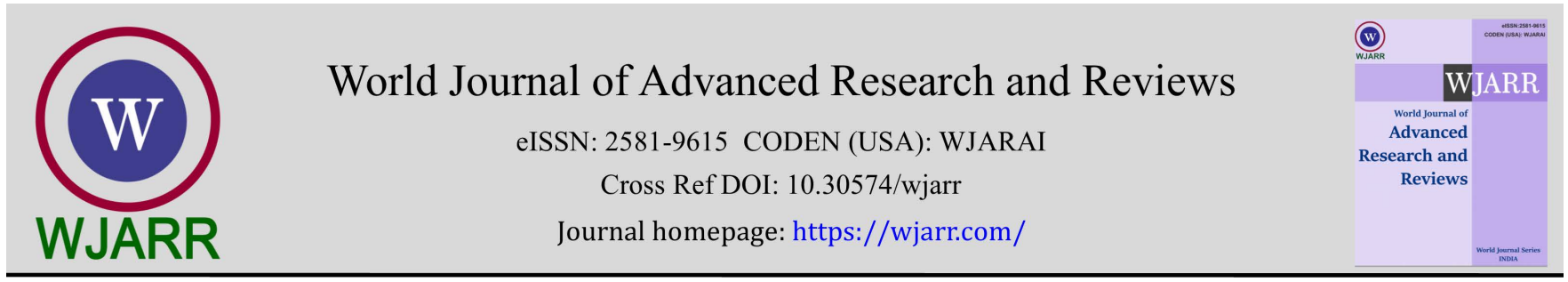

(RESEARCH ARTicle)

Check for updates

\title{
Analysis of land use change in Mangrove of the Barra San José, Chiapas, Mexico
}

\author{
Karla Mildred Cigarroa-Alonso ${ }^{1}$, Gladys Linares-Fleites ${ }^{2, *}$ and Miguel Ángel Valera-Pérez ${ }^{2}$ \\ ${ }^{1}$ Postgraduate in Environmental Sciences from Institute of Sciences, Meritorious Autonomous University of Puebla, Mexico. \\ ${ }^{2}$ Research Department in Agricultural Sciences from Institute of Sciences, Meritorious Autonomous University of Puebla, \\ Mexico.
}

World Journal of Advanced Research and Reviews, 2022, 13(01), 153-159

Publication history: Received on 24 November 2021; revised on 04 January 2022; accepted on 06 January 2022

Article DOI: https://doi.org/10.30574/wjarr.2022.13.1.0743

\begin{abstract}
Mangroves are the most productive ecosystems in the world, since they provide ecosystem services, are biological filters, stabilize the coastline and are the habitat of important fishing species and migratory birds nest. However, the inadequate implementation of agricultural, livestock and tourism development policies has implied the loss of biodiversity, habitat fragmentation and deforestation. The objective of this work is to evaluate the dynamics of changes in mangrove cover and land use in Barra San José, Chiapas, Mexico, in the period 1978-2017. The detection of the changes was carried out by means of a post-classificatory multitemporal study, through the superposition of digital cartographic bases of land use of the series III and VI of the INEGI. Maps of change processes, deforestation rates, and change matrices were obtained. The results indicate a loss of 574 ha of Mangroves in 39 years, with a deforestation rate of $-0.41 \%$, where human settlements and agriculture accounted for $90 \%$ of the changes. The conversion of Mangroves to grasslands was very marked, showing the fragmentation and loss of habitat to which the forests are exposed in the study area. The results of this analysis should be considered in the establishment of management and conservation policies for this ecological region.
\end{abstract}

Keywords: Ecosystems; Deforestation; Environment; Change processes; Chiapas's mangroves; Wetlands

\section{Introduction}

Mangroves are wetlands formed by arboreal and shrub vegetation located in coastal transition areas [1]. Mangroves provide numerous ecosystem services, including regulation of biogeochemical cycles, protection of the coastline, and fisheries production [2].

Despite the ecological importance of Mangroves, the implementation of agricultural, livestock and tourism development policies has implied the loss of biodiversity, habitat fragmentation, alteration of water flows and deforestation [3]. In Mexico, mangrove deforestation rates range from $0.85 \%$ to $1.05 \%$ [4], [5], [6] y [7]. Mangroves are highly vulnerable to the alteration of water flows.

These ecosystems have a great natural wealth that must be conserved and managed in a responsible and sustainable way, using the best information and technology available [8]. Based on a work coordinated by CONABIO [9] with the scientific community, governmental and non-governmental 81 mangrove sites were identified with relevance biological and with ecological rehabilitation needs at the national level. Of these, 10 correspond to the North Pacific region, six to the Central Pacific, 13 to the South Pacific, 27 to the Gulf of Mexico and 25 to the Yucatan Peninsula (cited in [8]).

\footnotetext{
${ }^{*}$ Corresponding author: Gladys Linares-Fleites

Postgraduate in Environmental Sciences from the Institute of Sciences, Meritorious Autonomous University of Puebla, Mexico. 
For the state of Chiapas, the reduction of Mangroves due to the expansion of the agricultural-livestock frontier has not been estimated. Due to the complications of field work in intertidal areas, it requires the use of Geographic Information Systems, which allow monitoring of environmental variables at different spatial and temporal scales such as changes in the size and shape of vegetation patches [10].

The objective of this research is to evaluate the dynamics and distribution of the processes of changes in mangrove cover and land use for the period 1978-2017.

\section{Material and methods}

\subsection{Study Area}

This study is restricted to the Barra of San José Wetland, Chiapas (Figure 1). The largest portion of the study area is subject to conservation as "La Encrucijada" Protected Natural Area.

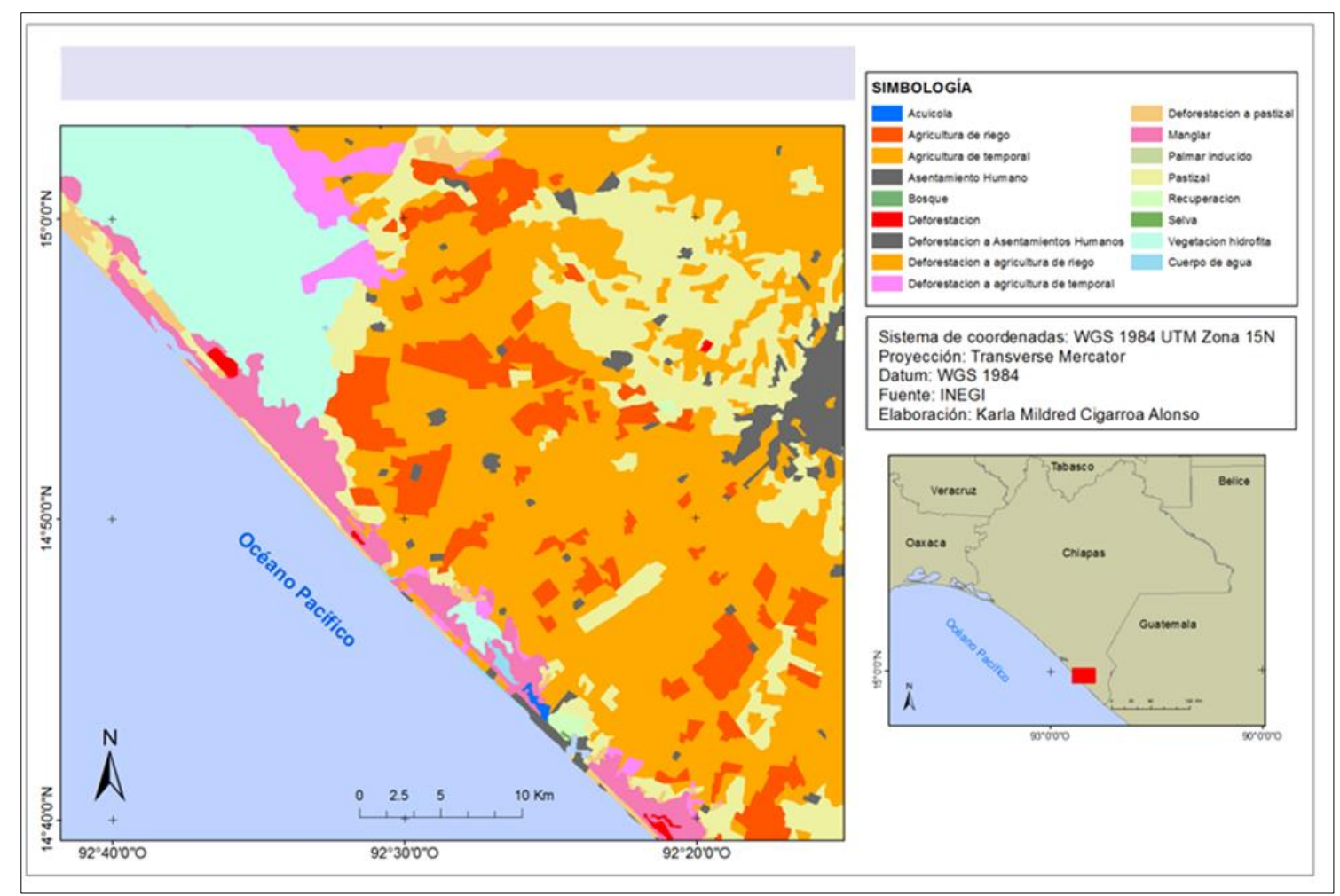

Figure 1 Map of change processes of Barra San José Wetland, Chiapas, 1978-2017

According to Koeppen's classification, it presents a warm sub humid climate, with an annual mean temperature of $27^{\circ}$ $\mathrm{C}$ and with precipitation, in the driest month, between 0 and $60 \mathrm{~mm}$. The percentage of winter rain is 5 to $10.2 \%$ of the annual total.

The bodies of surface water located in the study area are Barra San José and coastal lagoons associated with popales and tulares, which occupy around 567ha.

The predominant vegetation types are sub-evergreen, deciduous, sub-deciduous forest, hydrophytic vegetation, induced grasslands, mangroves, popal, tular, coastal dune vegetation, secondary vegetation, and cultivated areas.

\subsection{Information sources}

The cartography of land use and vegetation types prepared by the in the 80's (Series I) and in 2017 (Series VI), on a scale of 1: 250,000, was used [11]. The databases were subjected to several partial reliability evaluation exercises, which showed that they have quality within the international cartographic standards [12]. 
The classification system used for the analysis of land use change processes (Table 1) is hierarchical and it was decided to add the classes used in the INEGI classification system and adapt them to the classification system proposed by [13].

\subsection{Land use change processes}

The detection of the change processes of the different land uses was carried out by means of a multitemporal postclassification study, in an approximate analysis period of 39 years, which consisted of the superposition of two thematic maps of different dates (Series I, 1978 and Series VI, 2017), produced interdependently.

The matrices and exchange rates synthesize the main changes from time $t$ to time $t+n$ of the different categories present in the maps. The change detection matrix contains information on the change from one class to another, and its arrangement makes it possible to analyze the change between each of the classes present in the study area.

Table 1 Hierarchical legend to evaluate the processes of land use changes

\begin{tabular}{|l|l|}
\hline \multicolumn{1}{|c|}{ Reclassification } & \multicolumn{1}{c|}{ INEGI Classification } \\
\hline Agriculture (Farming) & $\begin{array}{l}\text { Irrigation Agriculture } \\
\text { Seasonal Agriculture } \\
\text { Cultivated forest } \\
\text { Aquaculture }\end{array}$ \\
\hline Human Settlements & $\begin{array}{l}\text { Urban areas } \\
\text { Human settlements }\end{array}$ \\
\hline Forest & $\begin{array}{l}\text { Oak-pine forest } \\
\text { Pine-oak forest } \\
\text { Oak forest } \\
\text { Oyamel forest } \\
\text { Cedar forest } \\
\text { Mesophyll forest of Mountain }\end{array}$ \\
\hline Water body & Water body \\
\hline Mangrove & Mangrove swamp \\
\hline Other types of vegetation & $\begin{array}{l}\text { Palm grove } \\
\text { Chaparral } \\
\text { Coastal dune vegetation } \\
\text { Popal } \\
\text { Tular }\end{array}$ \\
\hline Jungle & $\begin{array}{l}\text { Induced grassland } \\
\text { Cultivated pasture } \\
\text { Bed sheet }\end{array}$ \\
\hline Pastureland & $\begin{array}{l}\text { Deciduous forest } \\
\text { Sub deciduous medium forest } \\
\text { High and low evergreen forest } \\
\text { Medium and low sub-evergreen forest }\end{array}$ \\
Devoid of vegetation \\
\hline
\end{tabular}

The matrices and exchange rates synthesize the main changes from time $t$ to time $t+n$ of the different categories present in the maps. The change detection matrix contains information on the change from one class to another, and its arrangement makes it possible to analyze the change between each of the classes present in the study area. 
The data found on the diagonal of the change matrices represent the area that did not show any change in the period of analysis, while the data off the diagonal indicate the transitions from one class to another, in the form of gain or loss. (rows and columns respectively) between the two dates [14], which allows us to understand the dynamics of change in land cover and use at the local and / or regional level.

Subsequently, the areas for each land use and vegetation type were obtained, and deforestation rates were calculated according to the equation of FAO [15]

$$
\delta_{n}=\left(\frac{S_{2}}{S_{1}}\right)^{1 / t}-1
$$

where:

S1: area of the coverage on the initial date

S2: coverage area of the current date, and

t: period of time analyzed.

The calculation of the net annual loss for each type of vegetation was carried out with the following equation:

$$
P_{a}=\frac{\left(S_{2}-S_{1}\right)}{t}
$$

where:

$\mathrm{Pa}=$ annual loss in area,

$\mathrm{S} 1=$ area of the coverage on the initial date,

$\mathrm{S} 2=$ area of the coverage on the end date, and

$\mathrm{t}=$ period of time analyzed.

\section{Results and discussion}

The total surface of the study area is 62,916ha. The distribution of land use and vegetation in Barra San José was shown in Figure 1. It can be seen that the landscape is dominated by anthropic coverage, the agriculture class being the largest, followed by human settlements. Together, these change processes affect the forest areas that develop within the reserve.

\subsection{Deforestation rates}

The net loss due to land use for Barra San José is presented in Table 2. The highest deforestation rate (-0.41\%) was the Mangrove category, which meant a forest reduction of 574 ha, with an average loss of 15 ha per year.

The coverage that increased its surface exponentially are Human Settlements, which increased 913 ha at a rate of 8.9\%, while Agriculture increased 4,995 ha. Most of these changes are permanent, since the secondary vegetation did not show a significant recovery, and they are concentrated in the peripheries of the municipal capitals and urban areas.

These changes mainly affected the Forests that were reduced by 439 ha (-0.19\%); and the Forests represented $28 \%$ of the changes, with a forest reduction of 1,774 ha.

The coverage that increased its surface exponentially was Human Settlements, which increased

923 ha at a rate of 8.0\%, while Agriculture increased 5,009 ha. Most of these changes are permanent, since the secondary vegetation did not show a significant recovery, and they are concentrated in the peripheries of the municipal capitals and urban areas. 
These changes mainly affected the Forests that were reduced by 448 ha $(-0.19 \%)$; and the forests represent $28 \%$ of the changes, with a forest reduction of 1,792 ha.

The medium forests develop in areas with deeper and more fertile soils, with medium aptitude for agricultural and livestock activities, while the low forests are used to establish crops and pastures, the classes Other types of vegetation and Mangroves are being displaced by the advance of the agricultural frontier and the development of human settlements, which demonstrates the high rates of deforestation from forest systems to agricultural sites and the establishment of new towns (Figure 2).

Table 2 Rate of Land Use Change in Barra of San José Wetland, Chiapas, during 1978-2017

\begin{tabular}{|l|c|c|c|c|c|c|c|}
\hline \multirow{2}{*}{ Class } & \multicolumn{2}{|c|}{$\mathbf{1 9 7 8}$} & \multicolumn{2}{c|}{$\mathbf{2 0 1 7}$} & \multirow{2}{*}{$\begin{array}{c}\text { Net } \\
\text { change }\end{array}$} & $\begin{array}{c}\text { Annual loss } \\
\text { (ha) }\end{array}$ & $\begin{array}{c}\text { Rate of } \\
\text { change\% }\end{array}$ \\
\cline { 2 - 6 } & ha & $\mathbf{9}$ & ha & $\mathbf{\%}$ & 128 & 0.91 \\
\hline Farming & 11,84 & 18.82 & 16,85 & 26.7 & 5,009 & 128 & 8.03 \\
\hline Human Settlement & 48 & 0.08 & 970 & 1.54 & 923 & 24 & -0.19 \\
\hline Forest & 6,267 & 9.96 & 5,819 & 9.25 & -448 & -11 & 0.27 \\
\hline Water body & 510 & 0.81 & 567 & 0.90 & 57 & 1 & -0.42 \\
\hline Mangrove & 3,859 & 6.13 & 3,269 & 5.20 & -590 & -15 & -0.26 \\
\hline Other types of vegetation & 2,718 & 4.32 & 2,459 & 3.91 & -260 & -7 & -0.34 \\
\hline Pastureland & 25,25 & 40.14 & 22,07 & 35.08 & $-3,184$ & -82 & -0.40 \\
\hline Jungle & 12,354 & 19.64 & 10,562 & 16.79 & $-1,792$ & -46 & 4.53 \\
\hline No apparent vegetation & 62 & 0.10 & 347 & 0.55 & 285 & 7 & \\
\hline TOTAL & 62,916 & 100 & 62,916 & 100 & & & 7 \\
\hline
\end{tabular}

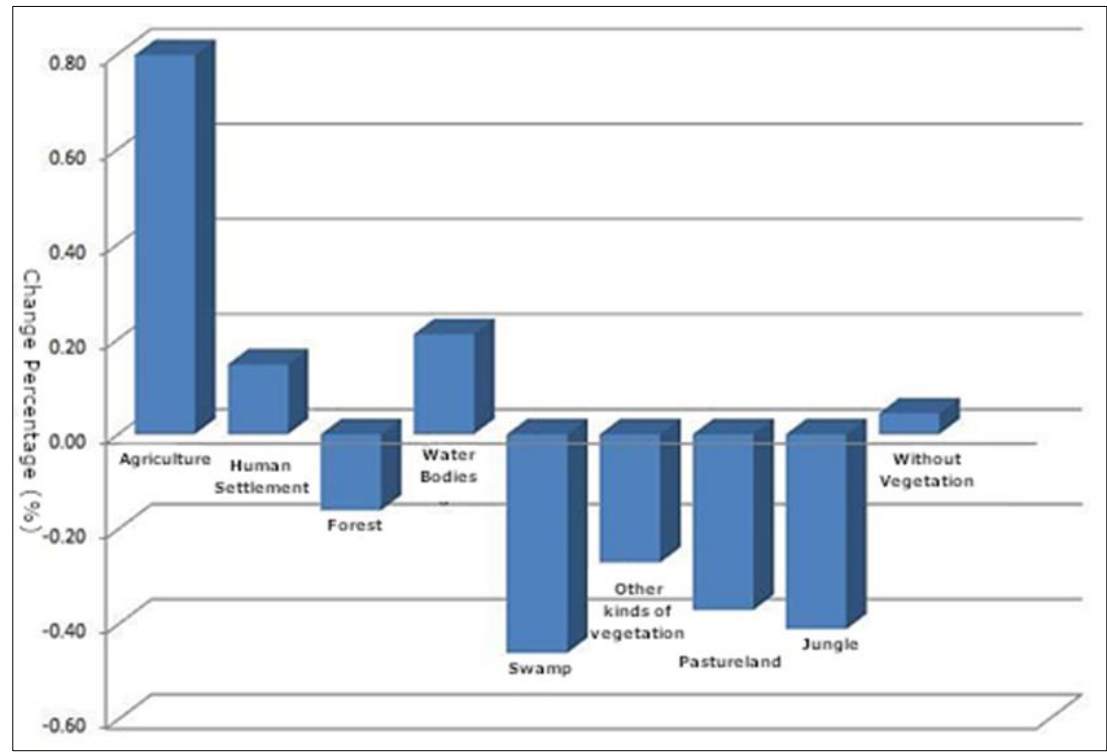

Figure 2 Graph of Exchange Rates in Barra of San José Wetland, Chiapas, for the period 1978-2017

The rates of Change by Land Use and type of vegetation mapped in Barra San José, Chiapas, during 1978-2017 are presented in Table3. It is observed that all the classes, with the exception of the Human Settlements, indicate probabilities of transition towards Grasslands. The dynamics of the shift from forests and jungles to agriculture and pastures is clear. An important exchange between the Mangrove and the Water Bodies is observed, denoted by the proximity between the classes, marking the strong dynamics between the transitional coastal ecosystems. Sites that are 
no longer productive, due to being scarce in forest resources, being abandoned crop plots or belonging to areas with overgrazing show high transitions to human settlements, as a reflection of a socio-cultural evolution.

Table 3 Surface exchange matrix and land use transition probabilities for the period 1978-2017

\begin{tabular}{|c|c|c|c|c|c|c|c|c|c|c|}
\hline & \multicolumn{9}{|c|}{2017} & \multirow[b]{2}{*}{$\begin{array}{l}\text { Total } \\
1978\end{array}$} \\
\hline 1978 & & & & & & & & & & \\
\hline & $9,813(0.83)$ & $274(0.02)$ & $482(0.04)$ & 5 & 22 & 15 & $1,024(0.09)$ & $191(0.02)$ & 2 & 11,89 \\
\hline & $1(0.03)$ & $33(0.97)$ & & & & & & & & 34 \\
\hline & $670(0.11)$ & 7 & $4,205(0.67)$ & & & 15 & $397(0.06)$ & $964(0.15)$ & & 6,258 \\
\hline & 1 & 1 & & $325(0.66)$ & $59(0.12)$ & $66(0.13)$ & $29(0.06)$ & $2(0.03)$ & 13 & 495 \\
\hline & $136(0.04)$ & 17 & & $122(0.03)$ & $2,664(0.69)$ & $258(0.07)$ & $505(0.13)$ & 25 & $117(0.03)$ & 3,843 \\
\hline & $280(0.10)$ & 21 & & 11 & $15(0.06)$ & $1,843(0.68)$ & $210(0.08)$ & $148(0.05)$ & 39 & 2,704 \\
\hline & $4,894(0.19)$ & $572(0.02)$ & 286 & 80 & 350 & 165 & $16,933(0.67)$ & $1,859(0.07)$ & 100 & 25,238 \\
\hline & $1,029(0.08)$ & 18 & $846(0.07)$ & 2 & 14 & 87 & $2,943(0.24)$ & $7,372(0.60)$ & 27 & 12,336 \\
\hline & & $5(0.09)$ & & $6(0.11)$ & $9(0.17)$ & & $2(0.04)$ & $2(0.04)$ & $29(0.56)$ & 53 \\
\hline $\begin{array}{l}\text { Total } \\
2017\end{array}$ & 16,824 & 946 & 5,819 & 551 & 3,270 & 2,448 & 22,043 & 10,562 & 326 & 62,789 \\
\hline
\end{tabular}

1: Agriculture. 2: Human Settlement. 3: Forest. 4: Body of water. 5: Mangrove. 6: Other types of vegetation. 7: Pastureland. 8: Jungle. 9: No apparent vegetation. (The number in parentheses corresponds to the transition probability for each category).

\section{Conclusion}

Accelerated deforestation and the intensification of anthropic activities, such as cattle ranching and agriculture, make good management and conservation of the Mangroves in the area difficult.

The Barra of San José Wetland, Chiapas, in a Protected Natural Area that has lost more than 570 ha of Mangroves since 1978 , due to the change in land use for agricultural use.

The dynamics of land use change in Barra San José Wetland, part of the easy clearing of the Low Forests and Mangroves to be converted to Induced or Cultivated Pasturelands. These sites are later used for the establishment of rainfed or irrigated Agriculture and, finally, after deforestation, the soils deteriorate are not so fertile or humid, and the fields of crops are abandoned to be transformed to new sites of Human Settlements.

Stopping deforestation in this important tropical region would mean retaining thousands of tons of carbon per year, which would have an impact on the reduction of global levels of atmospheric carbon, in addition to contributing to the conservation of biodiversity.

The execution of government policies that supported colonization and extensive cattle ranching throughout the Mexican southeast may be related to the Changes registered during 1978-2017 in Barra San José, Chiapas.

\section{Compliance with ethical standards}

\section{Acknowledgments}

We thank the Consejo Nacional de Ciencia y Tecnología (CONACYT) for the scholarship granted to the first author to carry out his postgraduate studies.

\section{Disclosure of conflict of interest}

The authors declare that there are no conflicts of interest. 


\section{References}

[1] Osborne PL. Tropical ecosystems and ecological concepts. 2000. Cambridge University Press. Cambridge. 464 p.

[2] Gir C, Ochieng E, Tieszen LL, Zhu Z, Singh A, Loveland T, Masek J, Duke N. Status and distribution of mangrove forests of the world using earth Observation satellite data. Glob. Ecol. Biogeogr. 2011; 20: 154-159.

[3] Romero H, and López B. Producción e integración del crecimiento urbano en el Municipio de Texcoco, Estado de México: periodo 1970-1989-1997. Investigaciones Geográficas Boletín del Instituto de Geografía UNAM. 2000; 42: 48-66.

[4] Díaz-Gallegos JR, Mas JF, Velázquez A. Trends of tropical deforestation in Southeast Mexico. Singap. J. Trop. Geogr. 2010; 31: 180-196.

[5] Hirales-Cota M, Espinoza-Avalos J, Schmook B, Ruiz-Luna A, Ramos-Reyes R. Drivers of mangrove deforestation in Mahahual-Xcalak, Quintana Roo, southeast Mexico. Ciencias. 2010 Mar; 36: 147-159.

[6] Leija-Loredo EG, Reyes-Hernández H, Reyes-Pérez O, Flores-Flores JL, Sahagún-Sanchéz FJ. Land use/cover change, and future scenarios in the coastal region of Oaxaca, State, Mexico. Madera Bosques. 2016; 22: 125-140.

[7] Soto-Galera E, Piera J, López P. Spatial and temporal land cover changes in Terminos Lagoon Reserve, Mexico. Rev. Biol. Trop. 2010; 58: 565-575.

[8] SEMARNAT. POLÍTICA NACIONAL DE HUMEDALES. 2016.

[9] Comisión Nacional para el Conocimiento y Uso de la Biodiversidad (CONABIO). Sitios de manglar con relevancia biológica y con necesidades de rehabilitación ecológica. CONABIO. 2009.

[10] Sherrouse BC, Clement JM, Semmens DJ. A GIS application for assessing, mapping, and quantifying the social values of ecosystem services. Appl. Geogr. 2011; 31, 748-760.

[11] National Institute of Geography and Information Statistics (INEGI). Serie I y Serie VI, 2017.

[12] Mas JF, Velázquez A, Díaz-Gallegos JR, Mayorga-Saucedo R, Alcántara C, Bocco G, Castro R, Fernández T, PérezVega A. Assessing land use/cover changes: A nationwide multidate spatial database for Mexico. Int. J. Appl. Earth Obs. Geoinf. 2004; 5: 249-261.

[13] Velázquez A., Más JF, Díaz-Gallegos JR, Mayorga R, Alcántara C, Castro R, Fernández T, Bocco G, Palacio JL. Patrones y tasas de cambio del uso del suelo en México. Gaceta Ecol. 2002; 62: 21-37.

[14] López E, Bocco G, Mendoza M, Duhau E. Predicting land-cover and land-use change in the urban fringe A case in Morelia city, Mexico. Landsc. Urban Plan. 2001; 55: 271-285.

[15] FAO. Forest resources assesment 1990. Survey of tropical forest cover and study of change. FAO Forestry Paper. $1996 ; 130$. 